\title{
A GROUP INTELLIGENCE SCALE FOR PRIMARY GRADES
}

\author{
A THESIS
}

Presented to the Faculty of the Graduate School of the University of Minnesota in Partial Fulfillment of the Requirements for the Degree of Doctor of Philosophy

BY

FRANCES ERMA LOWELL 


\title{
A GROUP INTELLIGENCE SCALE FOR PRIMARY GRADES
}

\author{
By Frances Lowell, University of Minnesota
}

\section{INTRODUCTION}

In October, 1917, the writer began a survey of all the schools in one of the representative counties in Minnesota, for the purpose of locating all cases of subnormality. ${ }^{1}$ Such a survey necessitates, among other things, visiting every school in the county, selecting all children of questionable mentality, and testing them, individually, with the Binet-Simon tests.

The selection of retarded and subnormal children above the third grade is relatively easy, for teachers' estimates, previous school records, and repetition of grades without the excuse of a long continued absence taken together form a fairly accurate basis. However, such methods are practically impossible in and below the third grade. This is due to several factors: first, to the inaccuracy of the school records for primary grades; second, to the frequent change of teachers, especially in the rural schools; third, to the fact that many children have been in school too short a time to become sufficiently retarded pedagogically to suggest a diagnosis of mental deficiency; and fourth, to the inability of many children, on entering school, to do themselves justice in the grade because of the strangeness of the new environment. Other difficulties, common to all grades, are also encountered in such a survey. Teachers frequently persuade themselves that since a child is sweet, docile and attractive, he must necessarily be bright; or, because he is doing good work in his grade, he is undoubtedly normal, regardless of the fact that he is two or three years older than his classmates. In one rural school, the teacher, on being asked about the work of twin girls in the third grade, said with great assurance, "Oh, those girls are very bright. They do good third grade work, and they are such nice children." The twins in question had a chronological age of twelve years, a fact entirely overlooked by the teacher in her estimation of their ability. Mentally, they were found to be

${ }^{1}$ This survey was made under the direction of Dr. Fred Kuhlmann, Director of Research, Faribault, Minnesota. 
$75 / 8$ and $83 / 8$ years, respectively, when given the Binet tests. Hence, in order to have an accurate survey, the need for an impersonal method of selecting children of doubtful mentality was imperative.

\section{History of Group Tests}

At the time the survey was undertaken, no group scales of intelligence had been published. Many single group tests had been standardized and published, but these, alone, are insufficient for making even a rough classification of children. However, within the past year, two scales have appeared, namely, one given in the "Mental Survey" ${ }^{2}$ and "A Group Point Scale." cussed here because they are intended for adults only, and, too, because they have not been published.

Pintner, in his "Mental Survey," recognizes the need for standardized survey tests for selecting individuals for further examination and for special promotions in the schools. To provide such a scale, he uses well known tests, namely:
1) Rote memory
2) Digit-symbol
3) Symbol-digit
4) Word-building
5) Opposites
6) Cancellation.

Norms, in terms of percentiles for each chronological age from six to sixteen inclusive, are given for each of the six tests. Each individual's record of actual attainment is taken for each test, and later translated into its corresponding percentile. The index of a child's mentality is found by getting the median of the six percentiles.

The reliability of the survey scale is checked by correlating results with those found by using the Yerkes Point Scale. In the sixth grade a correlation of only .29 was found; in the fourth grade a correlation of .59 existed, and in the second grade, one of .71 . When compared with results from Binet tests, the correlation was found to be .66 . These results tend to show, according to Pintner, "that we must not place too much reliability on the survey tests for individual purposes, but that for groups they give a fairly accurate measure of mentality."

\footnotetext{
${ }^{2} \mathrm{R}$. Pintner: The Mental Survey. 1918.

${ }^{3}$ S. L. Pressey and L. W. Pressey: A Group Point Scale. Journal of Applied Psychology. September, 1918.
} 
The Presseys took charge of the mental testing done in connection with the survey of a certain county in Indiana, which the Departments of Psychology and Sociology of Indiana University started in the fall of 1917. They, too, felt the need for group tests where large numbers of children were to be tested and so they tried to work out " a scale composed of tests which should be applicable over a wide range of ages -if possible from the second grade through high schooland which should be highly differential of general intelligence throughout this range."

The first requirement, in the selection of any test, is that its "beginning be easy enough and the directions clear enough so that nine-tenths of the $3 \mathrm{~B}$ children would make some score, and that the end of the test should be hard enough so that no one of the high school scphomores (averaging sixteen years old) would make a perfect score."

The second requirement for the tests, and the one which the Presseys consider the most original feature of their scale, is that of "careful adaptation in the nature of the tests, and in flexibility and ease in control of the class, for work with school children."

The tests used are:
1) Rote memory
2) Logical selection
3) Arithmetis
4) Opposites
5) Logical memory
6) Word completion
7) Moral classification
8) Dissected sentences
9) Practical information
10) Analogies.

The results of these tests have been worked out in terms of percentiles, and norms published for about one thousand children. Then the reliability of the tests in sorting out extreme cases was checked up by comparing group records of twentyone children found in the public schools-who, according to the Binet tests, had I. Q.'s of .76 or below-with records of normal children. It was found that the twenty-one cases "average at the 4 percentile of their age by the group tests; the highest scores made by these cases were at the 8 percentile."

The ability of the tests to sort out extreme cases was further noted in testing a group of " gifted " children with I. Q.'s above 1.25 , and also a group of children from an institution 
for feebleminded. The former group made scores averaging at the 98 percentile, whereas, in the latter group, only three were able to make a rating above the lowest 10 percentile of school children of the same ages.

Again, the age-grade status of children was compared with their rating by the group scale, and "the 143 retards in the ages from ten through sixteen average 70 points lower on their group test score than the 124 accelerates of the same ages."

The correlation of group test rank with teachers' rank, averages .65 .

Finally, in order to show the reliability of the tests as a measure of general intelligence, comparisons have been made between results from three cities for one age and also for one grade. "The results obtained by the group tests by age show an average difference for the medians of less than two points, whereas the differences by grade average thirteen points." In other words, if a comparison of results from a single age group, as eight, is made for each of three cities, there will be an average difference for the medians of less than two points. However, if one compares the results from one grade, such as the third, for each of the three cities, the difference for the medians will average thirteen points.

Although both the Pressey and Pintner scales seem to furnish a fairly reliable method for sorting and classifying large groups of children above the second grade, neither of them can be applied in the kindergarten or first grade, because children just entering school can neither read nor write, and both of these accomplishments are necessary to success in the Pintner and Pressey scales. Therefore, even had these tests been available in the fall of 1917 , they would not have been entirely satisfactory for the purposes of the writer.

\section{Purposes of the Present Scale}

In devising and standardizing the present group tests, the writer had two purposes in mind: first, to secure a scale for measuring the intelligence of large groups of children accurately enough to sort out all children of questionable normality. One could then be reasonably certain that these children, when tested individually by the Binet revisions, would be found mentally deficient, and the time ordinarily spent in testing cases wrongly estimated by teachers to be subnormal, would be saved.

The second purpose was to obtain a group scale which would discriminate between dull, average and super-normal 
children in kindergarten and primary grades. One finds here children who, regardless of their chronological age, are mentally capable of attempting the school work of the next higher class. On the contrary, some children will succeed better if permitted to remain a second term in one grade, and receive special help in overcoming individual difficulties. Still others, though chronologically eligible, should be kept at home or in kindergarten, until their mental age justifies their entrance into the first grade.

The importance of correctly selecting and placing the children of various degrees of mentality at the very outset of their school life, is realized when one considers that a dull child who attempts the same work as a normal child becomes so discouraged by his constant failures, and so overwhelmed by the hopelessness of the task, that it takes years to overcome the resulting lack of self-confidence, and to make him exert his best effort; whereas, the gifted child, for whom the work of the first grade is too easy, forms unfortunate habits of study, becomes uninterested and often troublesome. Meanwhile, taxpayers bear an unnecessary burden when children have to repeat grades or are allowed to spend a whole year on work which might have been done in half the time.

So with the object in view of supplying a possible solution for the problems involved in school promotions, as well as the more immediate purpose of securing a group scale for sorting out subnormal children for the survey, the present series of group tests to be used in primary grades was devised.

Some of these group tests are adaptations of the original Binet-Simon tests; some have been taken from Dr. Kuhlmann's 1917 Revision and others from Dr. Terman's Revision; still others were suggested by tests standardized by the Bureau of Analysis and Investigation in New York; and the rest are original.

\section{The Principles Involved in the Selection of Tests}

The requirements of the group test are many, for not only must it possess the characteristics necessary to the individual test, but it must also satisfy various other demands. Simplicity is an important criterion in the selection of the group test: simplicity of material, of directions, of response, and of scoring.

Since a large number of children must be tested at one time, it is necessary that tests be selected in which the material used can be easily carried and quickly distributed. In order to facilitate handling, and to avoid confusion, the writer has ar- 
ranged the material for the group tests in booklets. To each child, who has been in school less than one year, i. e., who is in the first grade, and hence can read and write but little, a booklet, $7 \frac{1}{2}$ in. $\times 71 / 2$ in., is given, which contains material and blanks necessary for the fifteen tests designated as five, six and seven year tests. Children in the second grade receive similar booklets designed for six, seven and eight year tests; while third grade pupils get booklets for the seven, eight and nine year tests. Thus, all the responses of each child are kept together, and confusion incurred by distributing and collecting loose sheets of paper every few minutes is avoided. All pages of the booklet are numbered, and definite spaces are allotted to each test. All possible elimination of disturbing elements is important, for in the primary grades the attention of the children is easily distracted.

Not only must the material for the tests be simple, but the directions to be followed must be clear and brief. Herein lies the greatest difficulty in selecting tests for a group. Frequently one feels confident that the directions for a certain test are perfectly clear and that they could not possibly be misunderstood, and yet when the test is given to a group of children, he finds that the meaning is entirely lost. Good English must frequently be sacrificed, for the child in the primary grades is surprisingly limited in vocabulary. Originally, in giving the directions for one of the six year tests, the writer said, "Make a cross in the LARGEST square." The result was puzzling, for the children crossed the smallest square as often as they did the largest. The test apparently was a failure for that age group. However, before discarding it, the writer decided to experiment a little to see if the difficulty could be discovered. Instead of having the children cross the square, they were asked to point to the largest square, whereupon one little girl tearfully informed the writer that she "didn't know what that meant." That solved the problem. From then on the children were instructed to "Make a cross in the BIGGEST square," and the success of the test was assured. Brevity is equally essential in giving directions to children, for their habits of thinking, of concentrating the attention, are not yet formed, and to listen, comprehendingly, to long directions is impossible for them. Novelty and change are so obviously important in maintaining the interest and stimulating the child to his best effort, that further discussion of the value of brevity is unnecessary.

In the selection of group tests, only those should be chosen which permit of but one correct response, and that response 
must have but one possible interpretation. It is true that some of the tests consist of several trials of the same sort; thus, three different series of five digits each, are read to the children, to be reproduced, but the child passes the test if he succeeds in reproducing any one of the series correctly. This is a necessary procedure, because it is almost impossible, in a group, to have perfect silence while the directions are being given; and so a single series might not be heard by all. Then, too, many children have poor auditory imagery, which fact makes it difficult for them to reproduce material presented orally. However, in all of the tests a response is either entirely correct or it is entirely wrong. This "All or none" method of scoring is used in the writer's group tests, for the purpose of the series is not to discover how much better one child can perform a given task than another, but to see which children fail to perform it at all, i. e., to sort out the subnormal children who need to be given the individual tests before a correct diagnosis can be made regarding their mentality. That the responses must permit of no variation in interpretation, due to the examiner's judgment, is undoubtedly as essential in group tests as in the individual tests.

Altogether, twenty-five tests have been selected which seem to fulfill the requirements mentioned above. These have been divided into groups of five, designated for convenience, as five, six, seven, eight and nine year tests. These have been given to 904 school children distributed according to age as shown in Table I.

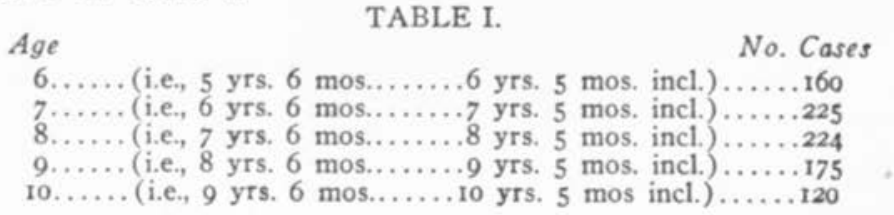

Total $\overline{904}$

\section{Description OF THE TESTS TESTS FOR YEAR $\mathrm{v}$}

\section{$V, I$. Formboard.}

Materials. This is an adaptation of Goddard's' formboard. From heavy white cardboard the ten well-known forms are cut. Black paper is pasted over the back of the openings to make them stand out more clearly, and then another sheet of

\footnotetext{
4Goddard: The Training School. Vol. IX, N, 4, June, 1912, pp. $49-54$.
} 
white cardboard is pasted over all this to form the back. Ten little cards which exactly fit the ten forms, are placed in an envelope pasted on the back of the formcard.

Procedure. The examiner holds up a booklet in front of the group of children to be tested, and says:

"Open these little books to this black and white card. In the envelope on the back you will find a number of little cards. Take these out of the envelope and put them in a pile on your desk. Now, there is one place in the black and white card into which each of these little cards will exactly fit,--like this. (Illustrate with square.) See if you can find the place for each of the others."

Help may be given any child who has difficulty in finding the place for each card the first time. When all the children have the cards properly placed, have them remove them and again place them in a pile on the desk. Then proceed as follows:

"Now you know where each little card belongs. This time we are going to see who can put all the cards in their places first. Everyone wait until I say 'Go,' and then work as fast as you can until I say 'Stop.' Then put your hands in your laps AT ONCE, without touching a single card again. Is everybody ready? Go."

Allow 50 seconds before giving the signal to stop. Care must be taken to see that no child touches a card after he has been told to stop.

Scoring. The test is passed if all ten cards are in their proper places at the end of 50 seconds. A plus or minus, indicating whether the child has passed or not, can be quickly marked on the blank page opposite the form card, by the examiner, before having the children replace the cards in the envelope.

\section{V, 2. Counting 4 Circles. (Lowell)}

Materials. A card, 6 in. $\times 18$ in., on which are printed four large circles about 2 inches apart, is necessary, and also two wooden blocks or other small objects. Space for the child to make the crosses is provided at the top of page 2 of the booklet.

Procedure. 'When I say, 'Make a cross,' this is what I want you to make. (Make $\mathrm{X}$ on the blackboard.) If I should say "Make a cross for each of these blocks (holding up two blocks), how many crosses would you make? Yes, two,-one for this block, and one for that (XX), see?' 
"On this large card are some circles. When I hold the card so you can see them, you are to count the circles TO YOURSELVES, and then make as many crosses up here at the top of your paper (Indicate) as there are circles. Ready. Look." Expose the circles for 10 seconds.

Scoring. The test is passed if four crosses are made.

\section{$V$, 3. Copying Square. (Binet)}

Materials. Use a large cardboard on which an eight inch square is printed in heavy lines.

Procedure. Holding up the large square, and indicating the space in the booklet to be used, the examiner says:

"At this side of the big space, here, see how nicely you can make a square just like this one."

Hold the card so all can see it while they are drawing, and then when they have finished one, say:

"Now see if you can make a still better one at this other side of the big space."

Scoring. The test is passed if one of the two squares drawn is as good as those on the score card used by Binet.

\section{$V$, 4. Discriminating Colors. (Binet)}

Since it is impossible to have children in a group test name colors, the following adaptation of Binet's color test was used. It necessarily makes a different test from the original, since the directions must be comprehended and followed exactly.

Materials. One-half inch squares of the red, yellow, blue and green, are pasted on page 2 of the booklet in the order named.

Procedure. "Look at the colors in the middle of this page. Listen carefully, and then do just as I ask you:

"1. Make a cross in the yellow square, like this.

" 2 . Draw a line through the green square, like this.

"3. Now make a cross above the red square, like this.

"4. Draw a line under the blue square, like this."

In order that the child shall understand what is wanted, draw a square on the board each time, and do what you tell the child to do. Give directions slowly, and repeat each.

Scoring. The test is passed if all four colors are correctly marked.

- Annee Psychologique (1911) vol. 17, pp. 145-201. 
$V$, 5. Irregular Tapping. (Pintner, ${ }^{\circ}$ Kuhlmann. ${ }^{\top}$ )

The present adaptation has been made from the form used by Dr. Kuhlmann in his 1917 Revision of the Binet Tests.

Material. Use a card, 6 in. x 18 in., on which are printed four squares, about two inches apart. At the bottom of page 2 in the booklet are three rows of squares similar to the one on the examiner's card.

Procedure. "At the bottom of the page you see three rows of squares. The first row looks like this one, doesn't it? (Point to card in hand.) Now I am going to tap some of these squares, like this. (Tap the first two squares with a ruler.) Watch me carefully, and when I've finished tapping, put a cross, like this, $\mathrm{X}$, in just the squares that I tap. 'Ready. Watch." Then tap the squares in Series A in the order named, at the rate of one square per second, and allow time between series for the child to cross the squares tapped. Always tell the children which row of squares to use for each series.
A) $1-2-4$
B) $1-3-4$
C) $2-3-4$.

Scoring. The test is passed if one of the three rows is correctly marked.

TESTS FOR YEAR VI

VI, I. Aesthetic Comparison. (Binet)

Material. On each of the pages 3,4 and 5 of the booklet are two pictures used by Binet for the comparison.

Procedure. "Look carefully at the two pictures on this page (3). Make a cross under the prettier one of the two." Give the same instructions for each of the pages 4 and 5 .

Scoring. The test is passed if the prettier face is indicated in two of the three series.

\section{VI, 2. Mutilated Pictures. (Binet)}

Materials. The four pictures used by Binet are printed on four successive pages in the booklet, 6, 7, 8 and 9 .

Procedure. "Look at this picture. (Page 6.) Part of the face is gone. Let us see what part it is. You see the eyes. Look, the eyes are there. You see the nose. Yes, the nose is there, and look, the chin is there. Now what part is gone?

- Pintner: A Scale of Performance Tests - r 1917.

${ }^{7}$ Kuhlmann: The Measurement of Mental Development - A School
Publication - Faribault - 1917. 
(Children name mouth.) Yes, the mouth is gone. Now make a cross right where the mouth should be, to show that that is the part that is gone.

"Look at the next picture. Do not tell me this time what is gone, just make a cross to show me what part is missing

"Make a cross to show what is gone from the next picture (Page 8.)

"And now show what is gone in the last picture." (Page 9.)

Scoring. The test is passed if the last three pictures are correctly marked.

\section{VI, 3. Counting Irregular Taps. (Kuhlmann)}

Materials. The examiner needs a wooden block or the blunt end of a pencil for tapping. Ruled blanks are provided the children on page 10 of the booklet.

Procedure. "Listen. I am going to tap on the table and see if you can count the number of taps. You count to yourselves, and give me the number when I ask you. Ready."

Tap 5 times, at the rate of one tap per second. See that the hand is screened, while tapping, by a large cardboard.

"How many times did I tap? Five, that is right. Now, instead of telling me how many times I tap, I want you to make a cross for each tap, when I get all through. I just tapped five times, so how many crosses shall I make to show it? Yes, five, like this: XXXXX.

"Sometimes I will stop tapping and then begin again. Don't let that fool you. You count only those you hear, and when I ask how many, you will make one cross for each tap, here, on this first line. (Indicate line each time.) Ready. Listen."

Tap the following series in order, at the rate of one tap per second, for each cross, and pausing a second for each dash:
1) $\mathrm{XX}-\mathrm{XX}$
2) $\mathrm{X}-\mathrm{XX}-\mathrm{XXX}$
3) $X X X-X$
4) $\mathrm{XX}-\mathrm{XXX}-\mathrm{X}$
5) $\mathrm{X}-\mathrm{XX}-\mathrm{X}-\mathrm{X}$

Scoring. The test is passed if 3 out of the five series are correctly counted as indicated by the correct number of crosses.

\section{VI, 4. Two Simultaneous Commands.}

This test was suggested by Binet's test in which three simultaneous commands were used. 
Materials. One row of circles and a row of squares of different sizes are provided for the children on page 10 of the booklet.

Procedure. "See these squares and circles. Listen carefully and see if you can remember what I am going to ask you to do with them, when I am all through telling you.

"Make a cross in the BIGGEST square.

Then draw a line in the FIRST circle.

"I will tell you once more, and then see if you can do both things. Listen :

"Make a cross in the BIGGEST square,

Draw a line in the FIRST circle."

Scoring. The test is passed if both directions are correctly followed.

\section{VI, 5. Perception of Sound. (Lowell)}

Material. A bean-bag, a baseball, a penny, a pencil, a key, and a wooden block are used. Have a table which can be concealed from the children and from which the above named objects can be dropped. A card picturing each of the objects with respective symbols to be drawn by the children, is tacked up in view of the children. See Fig. I. Space for six drawings is provided at the bottom of page 10 in the booklet.

Procedure. "What is this?"

Hold up each of the objects and have the children name it. "Now look at this card (Fig. I), and tell me what each of these pictures is. (Have them name them all.)

"Now I am going to drop each one of these on the floor] where you cannot see it, and I want you to listen to the noise each makes, and see if you can tell which of these I drop.

"If I should drop the bean-bag first, you would draw, in this first space, here, this. (Point to symbol at the side of the picture of the bean-bag); if I dropped the key next, you would make this $\mathrm{X}$ in the second space, here; if I dropped the penny next you would make this line in the third space, etc.

"Now shut your eyes, and see if you can tell from the sound which one of these I drop, and then look at the card to see what to draw. Then draw that in the first space. Ready. Listen." 
A GROUP INTELLIGENCE SCALE FOR PRIMARY GRADES 227
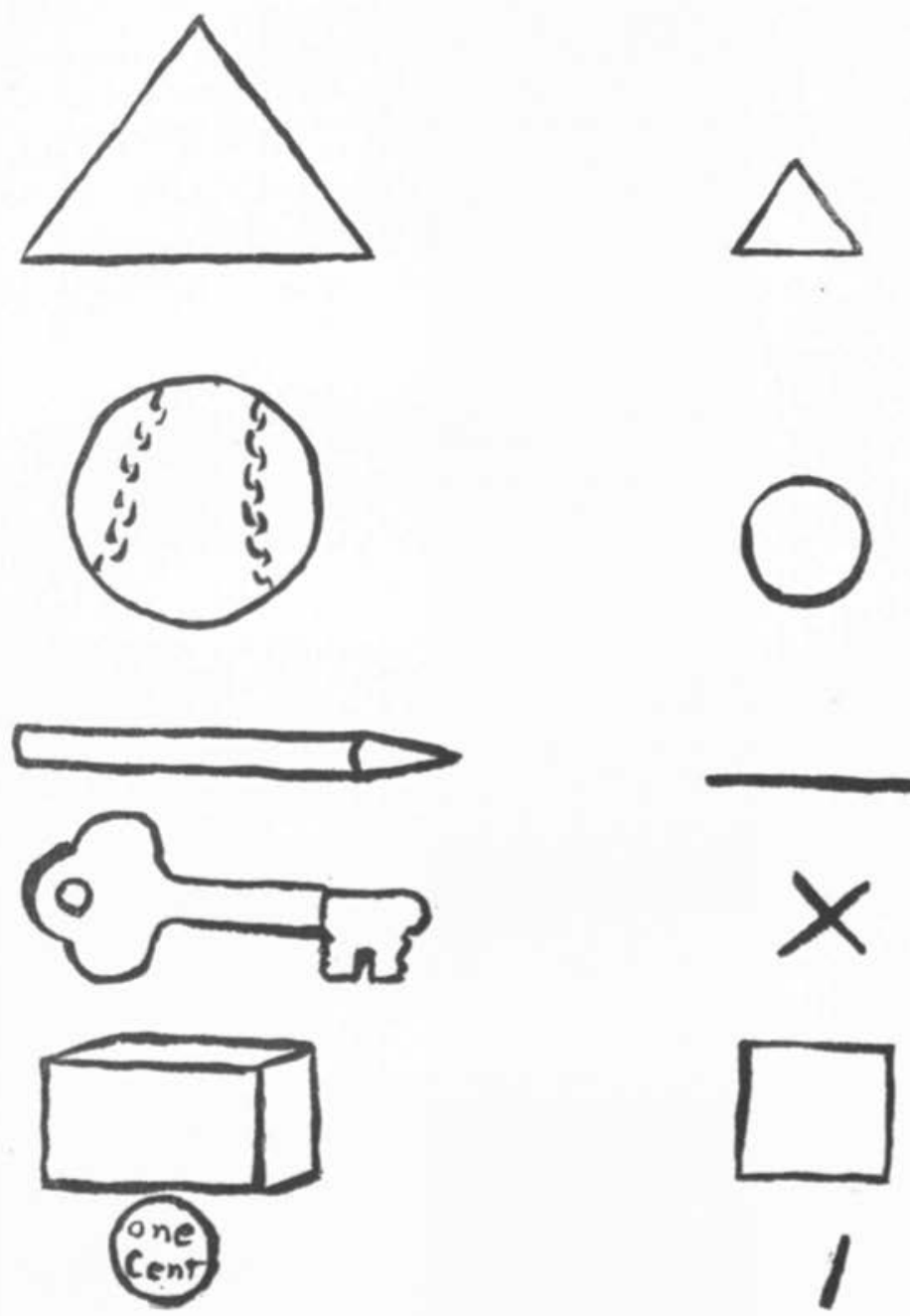

I

Figure I. (vi, s) 
Drop objects in the following order:

block
bean-bag
penny
key
ball
pencil

Scoring. The test is passed if five out of the six objects are named in the correct order.

\section{TESTS FOR YEAR VII \\ VII. I. Number of Toes.}

Because it is impossible to prevent a large group of children from counting their fingers if one were to use the original Binet test, the number of toes on each foot and on both feet together, has been substituted.

Procedure. "I am going to ask you some questions, and I want you to write the answers, here at A) and at C)— Ready:
A) How many toes on your left foot?
B) How many toes on your right foot?
C) How many toes altogether on both feet?"

Scoring. Since most children of seven years can make figures up to 10, further use of crosses in answering questions is not permitted. The test is passed if the answers to all three questions are correct.

\section{VII, 2. Memory Span. (Binet)}

Procedure. "I am going to read you some numbers. Listen carefully, and see if you can write them when I get through just the way I read them."

Read the digits at the rate of one digit per second, without rhythm.

"Listen:
A) $6-5-2-8-1$
B) $4-9-3-7-5$
C) $2-8-6-1-9$ "

Scoring. The test is passed if the digits in one series are correct, even though their order be changed. 


\section{VII, 3. Copy Diamond. (Binet)}

Material. Use a card on which a large diamond, 9 in. $\mathrm{x}$ 18 in., has been drawn in heavy lines.

Procedure. "At the left side of this big space, see how nicely you can draw a diamond just like this one."

Hold the card so that all can see it as they draw. After they have finished drawing the first diamond, say:

"Now draw another one at the right side of the big space just like this one."

Scoring. The test is passed if one of the two drawings is as good as those on the score card used by Binet.

\section{VII, 4. Tying Bowknot. (Binet)}

Material. Two pieces of tape, each about seven inches in length, are fastened to a stiff card pasted at the bottom of page 11 , in the booklet.

Procedure. "You know what kind of a knot this is, don't you? (Show them bowknot already tied). Yes, it is a bowknot. I want you to tie the same kind of a knot with the pieces of tape you have, just as quickly as possible."

Scoring. The test is passed if a bowknot is correctly tied.

\section{VII, 5. Geometrical Figures. (Lowell)}

Material. Use five cards, on which are printed, in a different order, on each card, a circle, a square, a cross, and a triangle. See Fig. II.

Procedure. "I shall show you some cards for ten seconds each. On each card you will find these forms. (Draw on blackboard.) But the order in each case will be different. On one card a square will come first, and on another card the circle will come first, etc. You will notice carefully the order of the forms, and when I take the card away, you will draw what you saw in just the order it was on the card. Draw as quickly as possible. Ready. Look at the first card."

Allow no more than one minute for reproducing a card.

Be sure all children are giving attention when you hold up a card.

Scoring. The test is passed if three of the five series are correctly drawn.

$$
\text { TESTS FOR GROUP VIII }
$$

$$
\text { VIII, I. Ball and Field. (Terman) }
$$

Material. The incomplete circle used by Terman to represent the baseball field, is printed in the booklet.

Procedure. "Let us suppose that your baseball has been 
lost somewhere in this round field. You have no idea what part of the field it is in. All you know is that the ball is lost somewhere in this field. You are to mark out a path to show me how you would hunt for the ball so as to be sure not to miss it wherever it might be. If you draw just a line to the center from the gate, like this,-it would mean that you only looked that far and then stopped,- - and the ball might be away over at the other side; you don't know where it is. Now
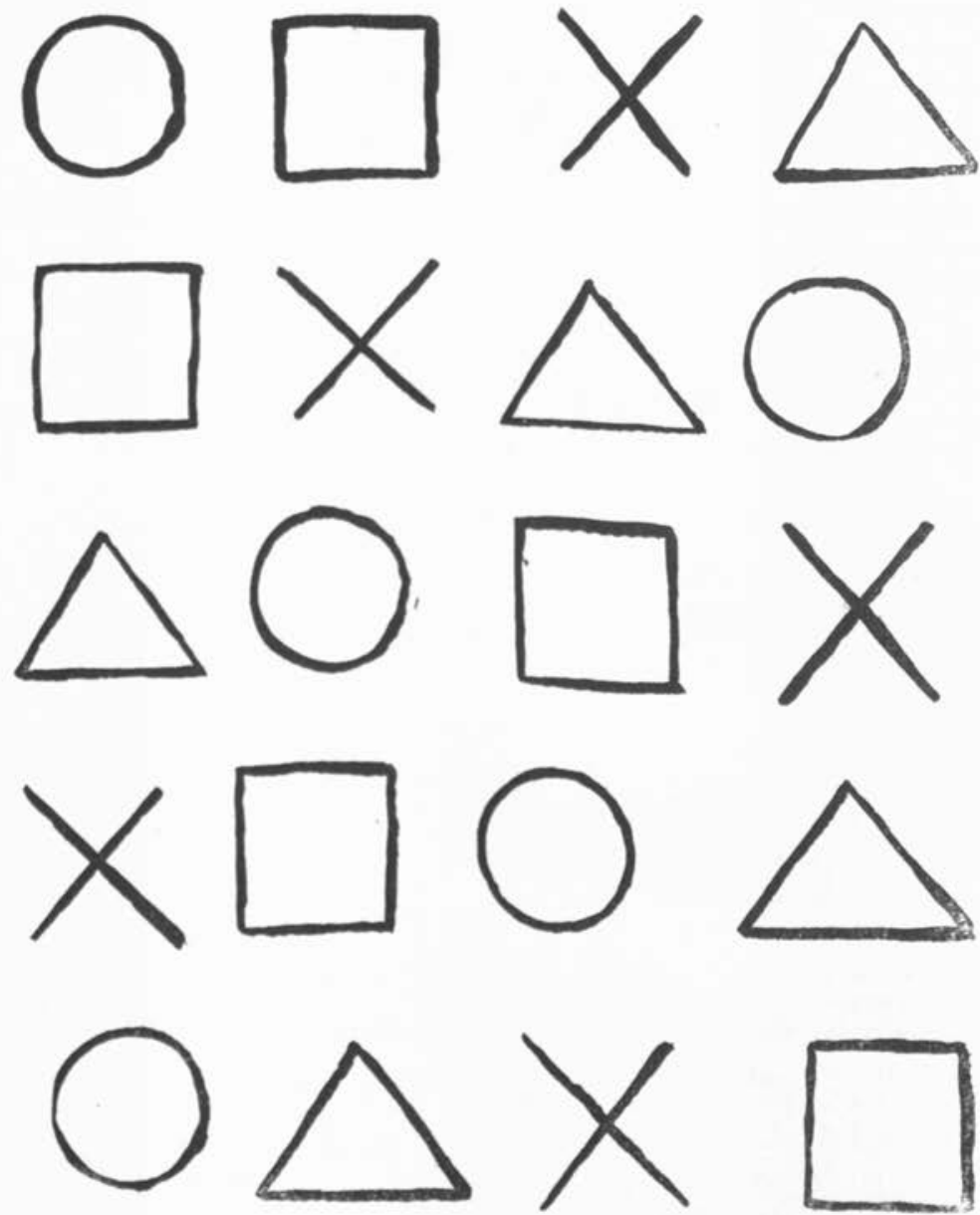

Figure II. (vii, 5) 
begin at the gate, and with your pencil mark out a path to show how you would hunt for the ball so as to be sure not to miss it."

In giving an individual child this test, according to Dr. Terman's directions, the examiner watches what the child draws, and if he stops after drawing just a short path, the examiner asks him where he would go next if he hadn't yet found the ball. As such procedure is obviously impossible with a large group of children, the illustration is used in the directions.

Scoring. The test is passed if the child shows a plan as good as those shown on Terman's score card for eight-yearold children.

\section{VIII, 2. Writing from Dictation. (Binet)}

Procedure. "I want you to write something for me as nicely as you can on this long line. Write these words: "See the little boy.' Be sure to write it all: 'See the little boy.',

Scoring. The test is passed if the sentence is written legibly enough to be easily read, and if no words are omitted. Unless a word is so incorrectly spelled as to make it unrecognizable, the error is not counted.

\section{VIII, 3. Counting the Value of Stamps. (Binet)}

Material. Use a cardboard on which have been pasted three one-cent stamps in a row at the top, and three two-cent stamps in a row under these.

Procedure. "Write the answer to this question on the short line here." Hold the card before the children and say:

"How much will it cost to buy all these stamps? A green stamp is worth one cent, and a red stamp is worth two cents. Now, how much are they worth altogether?"

Scoring. Test is passed if the answer, 9 cents, is given.

\section{VIII, 4. Comprehension Test. (Kuhlmann)}

Material. Three one-inch squares are printed in the booklet on page 3 .

Procedure. Point to the parts as you mention them.

"See this first square. This is the center of the square. What is it? This is the upper right corner of the square. What is it? This is the lower left corner. What is it? This is the middle of the left side of the square. What is it?

"Now take your pencils, and draw a straight line from the center of the first (second and third) square to:

1) The upper left corner. 
2) The middle of the upper side.

3) The lower right corner of the square."

Scoring. The test is passed if two of the three lines are correctly drawn.

VIII, 5. Estimation of length of lines. (Kuhlmann)

Material. On separate pages of the booklet are drawn three lines. The first line, drawn vertically in the center of the page, is three inches long; the second line, similarly drawn on another page, is two and one-fourth inches long; and the third line, drawn horizontally, and having two curves, is three inches long.

Procedure. "I want to see how well you can judge the length of lines without a ruler or even your pencils to help you measure. Look at this line carefully, and then draw a line under it here, horizontally, i. e., from left to right like this, (hold pencil where line is to be drawn), which is

1) Just as long and no longer than this line.

"Now look at this next line. Draw a line under it, here, horizontally, which is

2) Just twice as long as this one.

3) "Let's play that this is a piece of string. If I could take hold of the ends of it, and pull the string out straight, how long a piece would it be? Draw a straight line here, to show how long it would be." (Point to space under the curved line.)

Scoring. The test is passed if two of the three lines are drawn within one-half inch of the required length, i. e

1) 3 in.

2) $4 \frac{1}{2}$ in.

3) 3 in.

\section{TESTS FOR GROUP IX}

IX, I. Drinking Cup. (Bureau of Analysis, etc., N. Y.) ${ }^{8}$ Material. A square of white paper, $71 / 2 \times 71 / 2$ in.

Procedure. "I am going to show you how to make a drinking cup, and when I finish, I want you each to make one just like it. Watch carefully.

1st: Fold the square through the center like this.

2nd: Take the right hand corner and fold it over to the opposite side so that these two edges are equal.

\footnotetext{
${ }^{8}$ New York State Board of Charities, Bureau of Analysis and Investigation: Eleven Mental Tests Standardized, 1915, Eugenics and Social Welfare Bulletin No. V. p. 42.
} 
3rd: Next, take the other corner on the left side, and fold it over the same way so that the edges come straight across.

4th: Then, fold down this flap, and put it into this outer space to hold it.

5th: Now fold down the top flap for a cover, and you see how the cup looks.

"You take your square of paper now, and make one."

Scoring. The test is passed if the five folds of the drinking cup are correctly made.

$$
\text { IX, 2. Maze. (Porteus) })^{9}
$$

Material. The maze used by Porteus for nine year children, is printed in the booklet. See Fig. III.

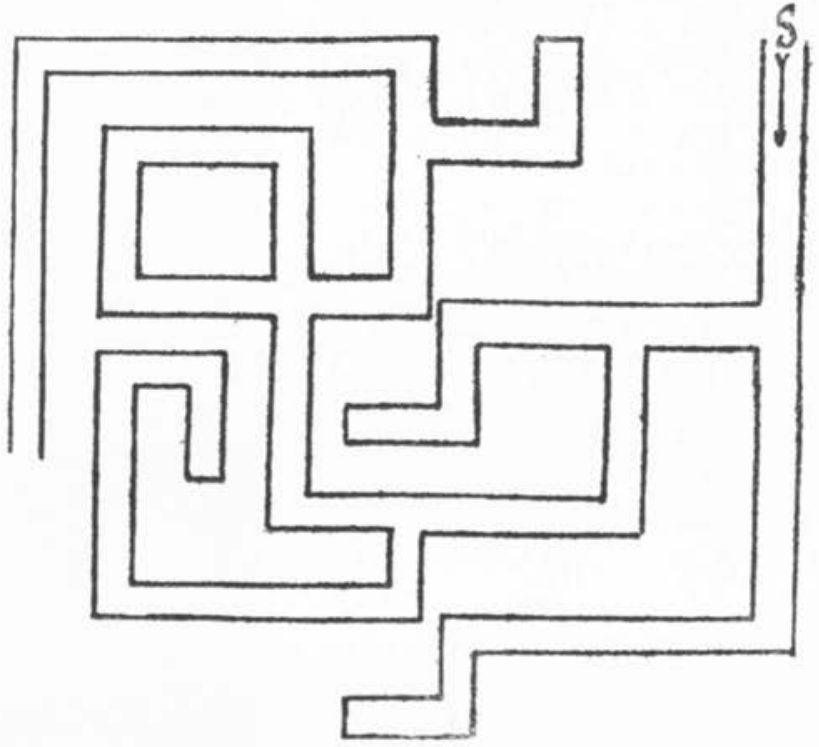

FIGURE III. (ix, 2)

Procedure. "Here you have a maze. Some of these paths are open, so you can get through, and some are closed at the ends. See how quickly you can find the shortest way out, without getting into any of the closed paths. Start where you

'Porteus: Mental Tests for Feeble Minded; Journal of PsychoAsthenics, Vol. 19, No. 4, June, 1915, pp. 200-213. 
see the letter $S$, and mark out the very shortest path you can find in order to get out over here on the other side. Do not stop to erase anything. If you make a mistake, just draw a line across it and go on as fast as you can."

Scoring. The test is passed if the shortest path is marked out in one minute, with not more than two errors. An error consists of a line, however short, drawn out from the shortest path.

\section{IX, 3. Tapping Squares. (Whipple) $)^{10}$}

Material. A sheet of paper is used on which a rectangle has been printed. This rectangle is divided into 150 half-inch squares, arranged in ten rows of fifteen squares each.

Procedure. "Please take your pencils and hold them firmly about half way up. Place your arm comfortably on the desk so that it may bend freely at the elbow. Now when I say, 'Ready,' you are to tap as many squares as you can, in order, without hitting any square twice, or missing a square, or touching any of the lines. Work until I say 'Stop." "

Scoring. The test is passed if 50 squares are correctly tapped in the 30 seconds allowed.

\section{IX, 4. Alphabet Test. (Kuhlmann)}

Procedure. "Of course you all know the letters of the alphabet, a-b-c-d-e etc. Who can tell me what is the first letter before 'C'? (B). Now who can tell me what is the sixth letter before ' $\mathrm{X}$ '? ( $\mathrm{R}$ ). Let us put this one on the brard, R-S-T-U-V-W-X. Notice that $W$ would be the first letter before $\mathrm{X}, \mathrm{V}$ the second, $\mathrm{U}$ the third, T the fourth, $\mathrm{S}$ the fifth and $\mathrm{R}$ the sixth.

"I will give you 30 seconds to answer each one of these questions.
1) What is the 3rd letter before $\mathrm{K}$ (H)
2) " 3 "
3) " $"$ " $"$ and " 4 "

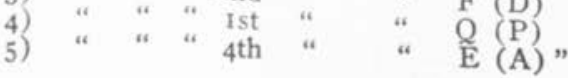

Always write the letter to be used as a basis on the board, so that the children will not misunderstand.

Scoring. The test is passed if three of the five letters are correct. II 5 .

${ }^{10}$ Whipple: Manual of Mental and Physical Tests, 1910. pp. 100- 


\section{IX, 5. Memory Test. (Kuhlmann)}

Procedure. "I am going to write five words on the board, and let you look at them for a few seconds. Then I will erase them and write five others and let you look at them, and so on with the other series. When I am through, I will give you the first word of a series, and you are to write down from memory, the other four words that go with it. Then I will give you the first word of the next list, and you will write the four that go with that one, etc. You must not write down any until I tell you to."

Let them look at each series for 30 seconds, then erase and take the next. Give them 30 seconds to recall each list. The lists are:

$\begin{array}{lllll}\text { Silver } & \text { red } & \text { kitchen } & \text { blackboard } & \text { lawn } \\ \text { spoon } & \text { cow } & \text { stove } & \text { teacher } & \text { grass } \\ \text { table } & \text { fence } & \text { flour } & \text { desk } & \text { tree } \\ \text { bread } & \text { clover } & \text { water } & \text { slate } & \text { house } \\ \text { fork } & \text { dog } & \text { spoon } & \text { lesson } & \text { walk }\end{array}$

Scoring. The test is passed if the child gives three series without more than one error in each. An omission counts as an error.

\section{Difficulties of Administering Group Tests}

Many problems, which from their very nature can never be entirely eliminated, arise in giving group tests to the primary grades. Some of these difficulties are due to the distractibility of young children, to their inability to comprehend directions readily, to their undeveloped moral sense, to the attitude of the teacher, and to the apparent inhibition of response which the nervous child exhibits.

The inability of the young child to attend to set problems for any length of time is a serious difficulty. It necessitates devoting almost the entire first year of his school life to the formation of habits of work, of play, of thought and of living. Up to the time of his entrance into school, he is permitted to eat, sleep, and play largely at will, but with the beginning of his educational career he is expected to live according to a more or less definite plan, regardless of his own wishes or pleasures. When a stranger tries to test forty such children, before regular habits have been formed, the difficulties encountered may easily be imagined. Usually, the children are sufficiently shy and timid not to need disciplining, but sometimes that very timidity prevents them from being responsive at first. Therefore, their confidence must be won by the time 
the booklets are distributed and the examiner is ready to begin the testing. The fact that the children are not permitted to look through the pages except as they use them for the tests helps to keep up the interest. When the booklets are finally distributed, the directions for the first test given, the children attentively (?) awaiting the signal to begin work, and then a little voice in the corner confidentially informs one that " $\mathrm{My}$ sister has some gold beads just like yours," the examiner wonders if he can ever be sure of a child's attention.

The difficulty experienced by young children in comprehending directions has been discussed under the "Selection of Tests." Frequent illustrations, full and explicit directions with numerous repetitions, all help the child in understanding what he is to do. However, ability to comprehend and follow directions accurately, is a test of intelligence, and too many or too great a variety of instructions may destroy the value of the test.

In order to stimulate the child to his best effort, one appeals to his competitive instinct, his sense of rivalry. This has its disadvantages, for the child in his eagerness to do better than his neighbor, or to get a word of praise from the examiner, resorts to methods "fair or foul." It is generally agreed that the young child is non-moral. The disapproval of the group has not been experienced sufficiently to make a lasting impression; and so the child slyly copies from his neighbor, or covertly writes on his desk the digits which are being read. To guard against such conditions as these, the writer has used various devices. Some have been mentioned under Procedure, such as having the child place his hands in his lap the instant he is given the signal to 'Stop ;' cover his work with his hands as soon as he has finished the task assigned; or, in the digits test, place the pencils on the desks and leave them there until told to write. In one or two instances, where the attention had several times been called, without effect, to the fact that someone in the room was not playing fair, more drastic measures have been taken, such as speaking to the child by name, or changing his seat. However, as most children are very sensitive to criticism, such measures are seldom necessary.

Frequently a teacher, not knowing the object of the group testing, feels that unless the pupils respond well to the tests, her reputation as a teacher will be at stake. In her anxiety to have the children make a good showing, she offers suggestions which help them. For example, when trying out various tests for the nine-year group, the writer used Terman's test 
of finding all the words that rhyme with "Day, mill and spring." In one third grade, the teacher felt that the children were not responding as readily as they should, so with much irritation she spoke to the class. "Why, children, you know how we have been finding words to go in the 'ING' family, so I don't see why you can't find others like 'Day' to go in the "AY' family." Of course the children could find words after that, but the test, as such, had lost its value. To avoid such incidents, the examiner should explain to the teacher at the outset that the purpose of the work is to see what each child can do by himself, without any suggestions from her.

So far, no difficulty has been experienced in securing the proper attitude on the part of the child, for the interest and novelty of the tests counterbalance any temperamental disturbances. However, it has been evident in the cases of several nervous children that the excitement produced by the competition, novelty and mental effort has inhibited responses, especially where the test has a time limit. If a pupil happens to be an only child and has not yet learned to adapt himself to an environment in which there are many children, he may fail to make an average score in the group tests, though when tested individually he may test even above normal.

\section{Table of Norms and How to Use It.}

If group tests are to be of value in selecting subnormal children, the number of tests passed by an individual must correlate with his age and intelligence. Table II shows the average number of tests passed by children of each chronological age and of the various I. Q.'s found in Grades I, II, and III.

As shown by the above table, the chronological ages of the children ranged from six to twelve years. By six years is meant all ages from five years six months to six years five months, inclusive; by seven years is meant all ages from six years six months to seven years five months, inclusive; etc. In order that the average number of tests passed by children of any age might serve as an index of their intelligence, individual I. Q.'s were obtained by means of Dr. Kuhlmann's 1917 Revision of the Binet tests, and then the average number of group tests passed for these various intelligence quotients and for each chronological age was computed. Thus, in using the table of norms in classifying an individual case, 
TABLE II

Norms. Average Number Tests Passed at Various Ages and Grades Grade I. (Group Tests V-VI-VII.)

I. Q. 6 yrs. $\quad 7$ yrs. 8 yrs. 9 yrs. 10 yrs. 11 yrs.

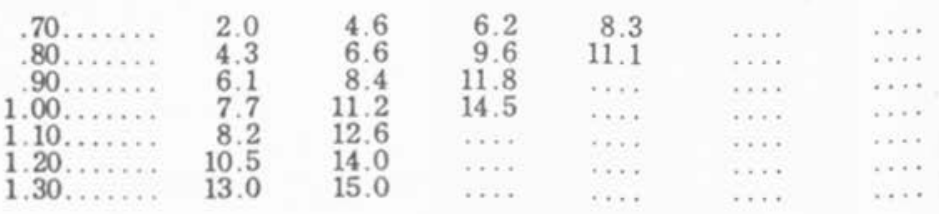

I. Q. Grade II. (Group Tests VI-VII-VIII.)

\begin{tabular}{|c|c|c|c|c|c|c|}
\hline $.70 \ldots \ldots$ & $\ldots$. & $\ldots \ldots$ & 7.3 & 8.6 & 10.1 & .... \\
\hline $80 \ldots \ldots$ & .... & & 8.8 & 11.0 & 12.0 & $\ldots$. \\
\hline $.90 \ldots \ldots \ldots$ & .... & 8.6 & 9.9 & 12.4 & 14.2 & $\ldots$. \\
\hline $1.00 \ldots \ldots \ldots$ & .... & 9.6 & 11.4 & 13.7 & .... & .... \\
\hline $10 \ldots \ldots$ & $\ldots$ & 10.1 & 12.5 & 14.5 & $\ldots$ & $\ldots$. \\
\hline $1.20 \ldots \ldots$ & 12.0 & $\begin{array}{l}11.5 \\
13.3\end{array}$ & 13.5 & $\cdots \cdots$ & $\cdots$ & \\
\hline 40 & 13.4 & 15.0 & $\ldots$ & $\cdots$ & $\cdots$ & \\
\hline
\end{tabular}

I. Q. Grade III. (Group Tests VII-VIII-IX.)

\begin{tabular}{|c|c|c|c|c|c|c|}
\hline 70 & & & & & & \\
\hline $80 \ldots \ldots$ & ....... & $\ldots$ & 8.5 & 8.0 & 9.8 & 10.3 \\
\hline & $\ldots . .$. & ..... & 9.5 & 9.2 & 10.8 & 11.6 \\
\hline $1.00 \ldots \ldots \ldots$ & & $\cdots$ & 100 & 10.2 & 11.9 & .... \\
\hline $10 \ldots$ & .... & $\cdots$ & 120 & 12.0 & 13.0 & $\ldots$. \\
\hline 20 & … & $\cdots$ & 131 & 13.5 & 14.2 & .... \\
\hline . & . & 12.0 & 14.2 & & $\cdots$ & \\
\hline $1.40 \ldots \ldots$ & $\ldots .$. & 14.0 & $\ldots$. & & & \\
\hline
\end{tabular}

one compares the number of group tests passed by him with the average number of tests passed by children of the same grade and chronological age, and finds the average in the series and its corresponding I. Q., with which his score agrees. For example, if an eight-year-old child in the first grade passed only seven tests, his score would lie between the average for children of his age who had an I. Q. of .70, namely 6.2 tests, and the average of those with I. Q. of 80 , or 9.6 tests. This would give him a group I. Q. of .72. Since such a rating would place him in the sub-normal group, he should undoubtedly be given the individual Binet tests, in order that his mental status be accurately gauged. 


\section{Reliability of the Group Tests}

In order to determine the reliability of any series of tests, the data must be considered from various points of view. The aspects which will be discussed in connection with the reliability of the present scale are; first, the discriminative capacity of the tests, i. e., their ability to distinguish between children of various ages, as shown by the increase in the per cent passing the tests for successive chronological ages; second, the percentage of children passing "at age," i. e., the percentage which will cause average six-year-olds to show a mental age of six years, average seven-year-olds to show a mental age of seven years, etc., as compared with the percentage passing at age in the individual tests; third, the ability of the group tests to discriminate between various mental ages in three school grades where the same group of tests has been given; fourth, the correlation between group and individual tests, as calculated by Karl Pearson's method; fifth, the agreement between group test results and school attainment; and sixth, the correlation between the writer's scale and an "Absolute Point Scale," ${ }^{11}$ when used on the same children.

\section{The Increase in Per Cent Passing for Successive Chronological Ages}

The discriminative capacity of group, as well as of individual tests, is measured by the increase in the percentage of children passing the tests from one age to the next. The greater the increase in the percentage passing any test from one age to the next, the higher is the discriminative capacity of that test.

Table III compares first, the percentage passing at age for each test in the five age groups, with the percentage of children, chronologically a year older, passing each test; and second, it compares the per cent increase from one chronological age to the next as found in the group tests, with the per cent increase found by Kuhlmann ${ }^{12}$ and Terman, ${ }^{13}$ where they have used the same tests in their revisions as individual tests. For example, 66 per cent of the six-year-old children passed the aesthetic comparison test (VI,1) when given in the group, and 75 per cent of the seven-year-olds passed it, thus giving

\footnotetext{
${ }^{11} \mathrm{G}$. Arthur and H. Woodrow: An Absolute Point Scale. J. Appl. Psychol. Vol. 3, 1919, pp. 118-137.

12 These figures were taken from results in Dr. Kuhlmann's revision, in which the tests had not been correctly placed in the scale.

13 Terman's results as quoted are taken from the data published in 1917 on the Stanford Revision.
} 
an increase from one age to the next of 9 per cent. When Kuhlmann used it as an individual test, he found an increase of 4 per cent passing from ages six to seven, and Terman found an increase of 6 per cent at the same ages.

TABLE III

Increase in Per Cent Passing for Successive Chronological Ages

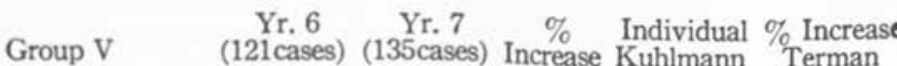

1. Formboard.... 65

2. Counting $4 \mathrm{Cir}$ cles..........

3. Copying square

4. Discriminating Colors.......

5. Irregular Tapping..........

Group VI.

$\begin{array}{cccc}\text { Yr. } 6 & \text { Yr. } 7 & \text { (122cases) } & \text { (136cases) } \\ \text { Increase Kuhlmann } & \text { Individual } & \text { \% Increa se } \\ \text { Terman }\end{array}$

1. Aesthetic Comparison......

2. Mutilated Pictures.........

3. Irregular Taps.

4. Two $\mathrm{Com}$ mands......

5. Perception of Sound.......

66

85

72

84

87

95

21

81

9

9

70

85

15

$\begin{array}{rrrrr}66 & 75 & 9 & 4 & 6 \\ 63 & 74 & 11 & 6 & 15 \\ 60 & 88 & 28 & \ldots & \ldots \\ 54 & 75 & 21 & \ldots & \ldots \\ 51 & 74 & 23 & \ldots & \ldots\end{array}$

Group VII.

$\begin{array}{cccc}\text { Yr. } 7 & \text { Yr. } 8 & \% & \text { Individual } \\ \text { (95 cases) } & \text { (198cases) } & \text { Increase } \\ \text { Increase } & \text { Kuhlmann } & \text { Terman }\end{array}$ 6

1. No. of Toes...

2. Memory Span.

3. Copy Diamond

4. Tying Bowknot

5. Geom. Figures.

$\begin{array}{lcccc}\text { Group VIII. } & \text { Yr. } 8 & \text { Yr. } 9 & \% & \text { Individual \% Increase }\end{array}$

1. Ball and Field.

2. Dictation......

70
63
84
72
61

88
81
92
81
76

18

3

$8 \quad 11$

76

$\begin{array}{rr}17 & 9 \\ 3 & 6 \\ 11 & 18 \\ \cdots & 16 \\ . . & . .\end{array}$

3. ValueofStamps

4. Comprehension Test........

70
78
70
72
69

79

87

84

9
9
14

$\ddot{20}$

7
8
17

5. Length of Lines

81

9 


\section{A GROUP INTELLIGENCE SCALE FOR PRIMARY GRADES 241}

$\begin{array}{ccccc}\text { Group IX. } & \begin{array}{c}\text { Yr. } 9 \\ \text { (106cases) }\end{array} & \begin{array}{c}\text { Yr. 10 } \\ \text { (112cases) }\end{array} & \begin{array}{c}\text { \% } \\ \text { Increase }\end{array} & \begin{array}{c}\text { Individual Kuhlmann } \\ \text { \% Increase }\end{array} \\ \text { Terman }\end{array}$

\begin{tabular}{|c|c|c|c|c|}
\hline $\begin{array}{l}\text { 1. Drinking Cup.. } \\
\text { 2. Maze.......... } \\
\text { 3. Tapping }\end{array}$ & $\begin{array}{l}67 \\
73\end{array}$ & $\begin{array}{l}78 \\
83\end{array}$ & $\begin{array}{l}11 \\
10\end{array}$ & $\therefore$ \\
\hline $\begin{array}{l}\text { Squares..... } \\
4 \text { Alphabet Test. } \\
5 \text { Memory Test.. }\end{array}$ & $\begin{array}{l}70 \\
73 \\
60\end{array}$ & $\begin{array}{l}79 \\
83 \\
71\end{array}$ & $\begin{array}{r}9 \\
10 \\
11\end{array}$ & $\begin{array}{l}. \\
\cdots\end{array}$ \\
\hline
\end{tabular}

Unfortunately, there are no other similar group tests published, with which the writer's percentages passing the various tests can be compared. However, there is about as much variation existing between the data from the two revisions of the Binet Scale as between the individual and group results.

\section{Per Cent Passing “at Age" in Individual and Group TESTS}

Considerable difference exists between the percentage of children passing "at age" in the group and in the individual tests. Kuhlmann has found that a much higher percentage of young children pass "at age" than of the older ones; thus, he found that 88 per cent of the four-year-old children pass the four year tests, whereas only 54 per cent of the twelveyear-olds pass the twelve year tests. However, in the group tests, the writer finds as small a percentage of six and seven year children passing six and seven year tests, as of nine-yearold children passing the nine year tests. Table IV compares the percentages passing "at age" as found by Kuhlman ${ }^{14}$ in the Individual Tests with those by the writer in the Group Tests. Thus, 78 per cent of the six-year-old children pass the six year Individual Tests, and only 60 per cent of them pass the six year group tests.

\section{TABLE IV}

\section{Per Cent Passing at Age in Individual and Group Tests} C. A.

Kuhlmann-Individual Tests . Lowell-Group Tests. 6 Yrs. 60
8 Yrs.
68
72
9 Yrs 64 68

The explanation of these differences in the six and seven year results may be found in the fact that a group test is largely a matter of comprehending and following directions

14 These figures were given me through the courtesy of Dr. Kuhlmann, from his manuscript of "The Measurement of Mental Developto be published soon. 
presented orally, without any individual help for individual needs. If a child has not been accustomed to doing things in a group, he will be easily distracted. Then, too, the younger the child the less capable he is of following instructions; but with each additional year of experience, and with an increasing mental age, the performance of tasks become easier. The effect of these two factors, namely, increasing mental age and increasing number of years in school, on the number of group tests passed, is shown in Table V.

\section{TABLE V}

Relation of M. A., No. Years in School and Av. No. of VII Year GROUP TESTS PASSED

M. A.

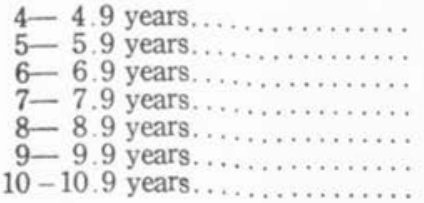

Average Number of Tests Passed in : Grade I Grade II Grade III

The data for the above table was obtained by testing 277 children individually, with Kuhlmann's 1917 Revision,-thus getting their mental ages. Then the average number of tests in the VII year group-this group was the only one of the three which was given in all three grades-passed by children of the various mental ages, was found for each grade. Thus, children with a mental age of $6-6.9$ years, who have been in school less than one year,- that is, who are in the first grade, on the average pass 1.2 tests of the VII year group; children of the same mental age who have been in school nearly two years, or are in the second grade, pass 3 tests; and those in the third grade, of the same mental age, pass 3.3 tests. So, with each additional year in school the number of tests passed increases, even though the mental age remains constant. On the other hand, with the "time in school" factor constant, but with increasing mental age, one also finds an increase in the number of tests passed. Thus, in grade I children whose mental age is $4-4.9$ years will not pass any of VII year tests; those whose mental age is $5-5.9$ will average 0.7 of a test; whereas those having a mental age of $8-8.9$ will average 4.0 tests.

These facts seem to indicate that two important principles are involved in the group responses of primary children. 


\section{A GROUP INTELLIGENCE SCALE FOR PRIMARY GRADES 243}

First, that the distractibility, so noticeable in kindergarten and first grade children, gradually decreases with each additional year of group or school performance, until it becomes, in the third grade, a negligible factor. In other words, the individual third-grade child has had time to adjust himself to his new environment, and to realize through frequent encounters with other members of the group, that his wishes and his behavior must conform to theirs. Second, mental age is an important consideration. This is true, however, only in so far as the work is sufficiently difficult to require effort on the part of the individual. Thus, in the third grade, taking carelessness and chance error into account, the maximal performance is reached, for the VII year tests, at a mental age of eight. Further increase in mental age does not improve the average eight year score.

\section{Correlation Between Group and Individual I. Q.'s.}

Since the standardization of the group tests has been completed, the writer has given the group tests to 153 children in the primary grades and found their group I. Q.'s. Then all of these children were tested individually by Kuhlmann's 1917 Revision of the Binet tests, and their individual I. Q.'s worked out. The coefficient of correlation, computed by Karl Pearson's method, for the two series of I. Q.'s is .77.

\section{Group and Individual I. Q.'s vs. School Attainment}

Individual records in group tests form a basis for promotion in primary grades, for the results obtained by group tests agree more closely with school attainment than do the results obtained by individual Binet testing. As a rule, children who give poor response to group tests, do poor school work, while those who obtain group I.Q.'s above 1.10 are capable of
special promotion.

On the basis of Terman's ${ }^{15}$ classification of normal or average children, namely, those having I.Q.'s from .90 to 1.10 , the 153 children mentioned above were grouped into three classes. Those having individual I.Q.'s below .90 were called dull, those with I.Q.'s from .90 to 1.10 , inclusive, were considered average or normal, and those with I.Q.'s above 1.10 were classed as superior. Then these cases were redistributed, on the basis of group I.Q.'s, into the same three classes. A comparison of the results is given in Table VI.

\footnotetext{
${ }^{15}$ L. M. Terman: The Measurement of Intelligence, 1916, p. 94.
} 
Table VI

Classification of 153 Cases by Group and Individual I. Q's.

Dull (Below .90) Average (.90 to 1.10) Superior (1.10+) By: No. Cases No. Cases No. Cases

$\begin{array}{llll}\text { Individual I. Q.'s.... } 27 & 27 & 80\end{array}$

Group I. Q.'s........ $49 \quad 66 \quad 38$

By this table, one notes that 22 more cases are rated as dull by the group scores than by the Binet I.Q.'s. School records of these 22 children offer the following bits of information: Case 1. RR. ${ }^{16}$

Case 2. Very poor school work, Marks average 70-76.
Case 3. R.

Case 4. RR.

Case 5. Deaf,- - hence class work unsatisfactory.
Case 6. RRR. Case 7. School work just passing - even with aid of special
help.

Case 8. R.

Case 9. Conditioned in grade. Neuropathic heredity. Does nothing in group, and only with much coaxing can information be elicited when the child is

Case 10. R. alone.

Case 11. R.

Case 12. Father of child f.m.- one brother an idiot - an

Case 13. R. aunt an idiot.

Case 14. R.

Case 15. Has very poor comprehension. Has to have much

Case 16. R. individual help.

Case 17. R.

Case 18. RR.

Case 19. Stammers very badly.

Case 20. Conditioned. Can only make grade with individual Case 21. R. help.

Case 22. R.

${ }^{16} \mathrm{R}=$ repeated work of grade.

$R R=$ repeated twice the work of the grade.

$R R R=$ repeated three times the work of the grade. 
Of the 66 cases classed as normal by the group tests, 53 receive a similar rating by the individual tests, and the other 13 were classed as superior. One must remember in this connection that a difference in an I.Q. of one point may change a child's rating from dull to normal or from normal to superior. For instance, a group I.Q. of 1.10 will place a child in the normal group, whereas an individual 1.Q. of 1.11 would classify him as superior, and vice versa. A difference in classification due to a difference of 3 points or less between group and individual I.Q.'s occurred in 5 of the 13 cases mentioned above. The school records of the other eight give the following comments:

Case 1. Slow to respond. Never volunteers to recite in class.

Case 2. Schoolwork inferior to Individual I. Q. Does poor team work.

Case 3. Lazy and careless - will not work if possible to avoid it.

Case 4. Doesn't work well in group - wants attention centered on self.

Case 5. Has been in school less than one year. Spent one day in each of Grades I and II and then was located in grade $3 \mathrm{~B}$.

Case 6. R.

Case 7. Can't adjust to conditions in a group either at work or play. Is irritable and nervous. Mother in-

Case 8. R. sane.

Agreement is very close between Group and Individual ratings of the superior group. One interesting case is found on school records for this class, namely that of a child who was doing such good school work that the teacher recommended a special promotion for him, although his I. Q. as determined by the Binet tests did not warrant it. In view of his excellent school work, and of the fact that when given the group tests his score placed him in the superior group, the child was given the extra promotion. He has been in the new grade nearly two months and is still doing superior work.

Careful consideration of available school records seems to indicate and in fact, to emphasize a closer agreement between group test results and school attainment than between Binet scores and school work. Such a correspondence is to be expected, however, when one realizes that the principles involved both in group testing and in school work are fundamentally the same. 
Correlation Between Two Group Intelligence Scales

While the present writer has been devising and standardizing a group intelligence scale by the "all-or-none" method, an "Absolute Intelligence Scale" ${ }^{17}$ has been constructed in which a point method has been used. Nine well known types of tests have been used, namely:

1) Immediate Memory Span

2) Easy Opposites

3) Hard Opposites

4) Substitution

5) Word Building

6) Language Completion

7) Anagrams

8) Cancellation

9) Comprehension

Without discussing the mathematical calculation of their points, a fairly accurate idea of the general plan of the scale may be obtained from the following quotation:

"The quotients which we have termed discriminative values represent an absolute increase in ability from one age to the next, for their respective tests. - The final absolute intelligence scale is secured simply by adding together the point scales of the individual tests. The normal absolute intelligence for any age is simply the sum of the normal point scores of that age for all nine tests."

This point scale differs from the all-or-none scale in practically every detail except that both are Group Intelligence Scales, and both can express their scores in terms of intelligence quotients. The two series of tests were given to a group of 77 children, and I. Q.'s for each scale computed. The coefficient of correlation between the two groups of I. Q.'s is 0.76 (Karl Pearson.)

\section{Summary}

The present group scale offers a means for measuring the intelligence of large groups of children accurately enough to sort out all children of questionable normality. It also forms a basis for school promotion and demotion in the primary grades.

It consists of 25 tests, arranged in groups of five, and for convenience, called five, six, seven, eight and nine year tests.

${ }^{17}$ Grace Arthur and Herbert Woodrow: An Absolute Intelligence Scale. The writer is indebted to Miss Arthur and Dr. Woodrow for their cooperation in comparing group results and for making their data available for the writer's purposes. 
The tests have been standardized on the basis of results obtained from 904 children of the ages five years six months to ten years and five months, inclusive.

The uncorrected coefficient of correlation (Pearson) between measurements made, in terms of intelligence quotients, by the Group Scale and by Kuhlmann's 1917 Revision of the Binet Tests is 0.77 .

The group results form a more accurate index of the child's performance, than do the individual results obtained by the Binet tests.

The uncorrected coefficient of correlation between two series of I. Q.'s obtained for 77 children by the present group scale and by "An Absolute Point Scale" is 0.76 . 